Canadian Journal of Fisheries and Aquatic Sciences

Canadian Science Publishing

Journal canadien des sciences halieutiques et aquatiques

\title{
Communicating uncertainty in quota advice: the case for Confidence Interval Harvest Control Rules (CI-HCRs) for fisheries
}

\begin{tabular}{|r|l|}
\hline Journal: & Canadian Journal of Fisheries and Aquatic Sciences \\
\hline Manuscript ID & cjfas-2015-0078.R1 \\
\hline Manuscript Type: & Article \\
\hline Complete List of Authors: & $\begin{array}{l}\text { Da-Oct-2015 } \\
\text { Sciences, Dorothy; University of Bergen, Centre for the Study of the } \\
\text { Volstad, Jon; Institute of Marine Research, } \\
\text { Aanes, Sondre; Norwegian Computing Center, }\end{array}$ \\
\hline Keyword: & $\begin{array}{l}\text { FISHERY MANAGEMENT < General, FISHERY RESOURCES < General, } \\
\text { FISHERY COLLAPSE < General, MARINE FISHERIES < General, harvest } \\
\text { control rule }\end{array}$ \\
\hline &
\end{tabular}

\section{SCHOLARONE \\ Manuscripts}


1

2 Communicating uncertainty in quota advice: a case for Confidence Interval Harvest

3 Control Rules (CI-HCRs) for fisheries

4 Authors: Dorothy Jane Dankel ${ }^{1,2,3 *}$, Jon Helge Vølstad ${ }^{2}$ and Sondre Aanes ${ }^{4}$

$5{ }^{1}$ Centre for the Study of the Sciences and the Humanities, University of Bergen, P.O. Box

67805,5020 , Bergen, Norway

$7 \quad 2$ Institute of Marine Research, P.O. Box 1870 Nordnes, 5817 Bergen, Norway

$8 \quad{ }^{3}$ Nordic Marine Think Tank, Ved Lunden 19, 4300 Holbæk, Denmark

$9 \quad{ }^{4}$ Norwegian Computing Center, P.O. Box 114 Blindern, 0314 Oslo, Norway

10

11

12

*Corresponding author: dorothy.dankel@uib.no

\section{Abstract}

Multi-annual management plans are important tactical arrangements to support upperlevel marine resource policies in many countries. The newly reformed Common Fisheries Policy in the EU reiterates the role of management plans, supported by the development of harvest algorithms, commonly called Harvest Control Rules (HCR). Current HCRs for most commercially important fish stocks in Europe and Norway depend on point estimates of the size of the spawning stock biomass (SSB) and level of fishing mortality $(F)$ to dictate the scientifically-recommended Total Allowable Catch (TAC). When annual TAC advice from the ICES Advisory Committee, for example, is based on a point estimate for SSB, the propagation of uncertainties (assessment models of varying complexity, variable data sources and variable degrees and structures of random and systematic errors) and subjective expert decisions is contained, at best, in an annex of the official ICES advice document. TAC advice given as an exact number (sometimes specified to the kilogram) often occurs when clients (who commission the advice, or ministerial or other government authority) expect more of science than science can deliver. We outline an alternative formulation of the HCR that 
27 reflects the knowledge base through confidence intervals (CIs) dictated by the quality of 28 input-data data from multi-stage sample surveys and model uncertainties. Our CI-HCR determines the TAC advice given the range of SSB and $F$ assessed and performed more robustly in face of uncertainties than the standard HCR formulation. The advantage of CIHCR is that the advised quota will depend on the quality of the assessments. Also, the adequate level of monitoring for advice support can be determined based on what science can actually provide.

Keywords: stock assessment, harvest control rules, confidence intervals, uncertainty communication, hidden uncertainties, unknown knowns, science for policy advice, fisheries models, technoscience

\section{Introduction}

Natural renewable resources, like those exploited in marine capture fisheries, are sources of economic, social and nutritional benefit for societies. The benefits society receives from these resources can be compromised by natural or human-induced fluctuations, and thus much research is devoted to understanding both the natural dynamics and how to effectively manage human exploitation of these renewable resources. Fisheries management in the developed world is typically built upon fisheries science and an understanding of how the managed fish stock grows and reproduces (Wilson 2009). Often, a single and conclusive scientific answer will never be available for complex systems such as fisheries. In such cases, more research does not lead to less uncertainty, but can lead instead to unforeseen complexities (Van der Sluijs et al. 2005; 2010; Trenberth 2010). Values are in dispute when the potential impacts of decisions based on uncertain science have very large biological and/or social consequences. But a transparent dialogue about this uncertainty and its consequences 
on science-based advice is not regularly practiced. We put forward a framework that explicitly accounts for the accuracy of the assessment results, i.e. the proximity of the estimate to the true value (Jessen 1978; Aanes and Vølstad 2015), in the decision process. Science-policy interfaces are virtual arenas of collaboration between scientists, decision-makers, and potentially, stakeholders. The dynamics of the science-policy interface include scientists and decision-makers and other stakeholders sharing and discussing scientific knowledge in light of current policy challenges. By doing so, new knowledge is created to aid in developing recommendations and ideas (i.e. regulations to change or control human behavior) for decision-making. Fisheries science for management is an interesting case of the science-policy interface (Dankel and Edwards, in press). In order to ensure the longterm viable exploitation of fish stocks (a natural renewable resource) policy and supporting fishing regulations are dependent on a solid basis of scientific assessments and scientific advice.

The formulations of the scientific fisheries advice vary among management organizations around the world. For example, the Regional Fisheries Management Organizations for tunas use a probabilistic stock assessment and a catch limit algorithm to recommend a level of catch (Cooke 1999), and in the Faroe Islands, an effort-based regime suggests a number of days-at-sea to fulfill management objectives (Hegland and Hopkins 2014). In the United States, annual catch limits fulfill national objectives of maximum sustainable yield (Methot et al. 2013).

The standard fisheries management science paradigm is that the quota advice, traditionally a single number formulated as the total allowable catch (TAC), is based on an analytical stock assessment that typically includes both fisheries-dependent and fisheriesindependent survey data (Hilborn 2003). Despite the different types of advice and national and regional semantics, every year for most all commercially important fish stocks, a number 
representing a quota is passed through the sub-arenas of the science-policy interface: science, politics and law. First, based on data from official landings statistics, biological sampling of catches and survey sampling of fish populations at sea, scientists conduct a stock assessment (e.g. ICES 2015), and based on their assessment of the size of the spawning stock and other parameters they recommend a quota for the next year. Holm and Nielsen (2004) describe the annual, routine process of running a stock assessment and producing this quota advice as the "TAC machine." The premise in fisheries management is that managers can control human behavior at sea, and hence fish stocks. In order to produce the TAC, the relationship between fishermen through fishing effort and fish (through stock assessment) must be quantified (Johnsen et al. 2009). Since fisheries management is typically based on scientific advice characterized by high uncertainties regarding the perception of the size of the stock, many have underscored the importance of communicating the different types of uncertainty to stakeholders and decision-makers (Charles 1998; Dankel et al. 2012; Hauge 2010; Punt et al. 2014; Wilson 2009, Wilson and Pascoe 2006).

The accuracy (precision and bias) of model-based stock assessments depend on process errors, as well as systematic and random errors in input data based on survey estimates of abundance and composition of the catch (in numbers at length or age) from a fishery and how these are weighted (e.g., Francis 2011). A characteristic of fisheries sampling is the hierarchical cluster sampling within the primary sampling units (PSU) that is needed to obtain the fish (or shellfish) that are actually measured or from which lengths age structures are collected (ICES 2014a). The precision in estimates of abundance indices and catch in numbers at age is largely driven by the number of primary sampling units (PSUs) (Nelson 2014; Aanes and Vølstad 2015). The precision in estimates that are input to stock assessments can be quantified, provided that the survey sampling design, execution, and estimators follow good scientific practice (e.g., ICES 2014a). Because the sample sizes of 
PSUs (e.g., trawls hauls, vessel-trips) generally are small, the precision of key input estimates can be low, even though a large number of fish is sampled (Aanes and Pennington 2003; Nelson 2014; Aanes and Vølstad 2015). Systematic errors related to factors such as poor survey design or biased estimators can be substantial (see e.g., Aanes and Vølstad 2015), but are difficult to quantify for empirical data.

In general, uncertainty is not accounted for transparently in fish stock assessment. The status quo is typically limited to documenting process error in the assessment models, while the systematic and random errors in the input data (to stock assessments) from highly clustered catch sampling are either ignored (e.g., Shepherd 1999) or underestimated (Nelson 2014; Aanes and Vølstad 2015) and not a standard, clear part of the advice. For example, the current ICES InterCatch data sharing system used by national institutes to upload national estimates of fish catches by length and age per area per time period per fleet etc. provides aggregated output files used as input for the stock assessment models. These aggregated data lack information on survey design and are decoupled from the PSUs and, hence, do not support the estimation of precision and assessment of sources of bias. These omissions could have substantial effect on the accuracy of the stock assessment which is the basis of the advice.

In this study, we focus on a case of a well-studied, data-rich, commercially important medium to long-lived stock, which uses point estimates of stock size to derive a TAC from a harvest rule, the Northeast Arctic cod (Gadus morhua). In Table 1, we illustrate how the TAC number (derived after the official ICES recommendation which then is negotiated by the coastal states) is re-interpreted in different contexts. Each of the three columns in Table 1 gives information on essentially the same topic: the quota for the Northeast Arctic cod stock for a given year. The number in each column is conceptually the same number, referring to the same understanding of the size of the quota, but contextually re-interpreted. This re- 
127 interpretation of the number (the quota) has consequences associated with risks: risk of the 128 biomass going below a reference biomass $\left(B_{\text {lim }}\right)$, risk that the fishing rate goes above the 129 precautionary rate $\left(F_{\mathrm{pa}}\right)$, or other reference point or objectives. Thus the propagation of 130 uncertainties can be seen as a snowball effect: random and statistical errors from the data 131 collection through the model output used for quota advice can have severe effects on the 132 advice.

Stock assessment estimates and quota advice are numbers that are important indicators to the highly commercialized fishing industries about how their business will run the coming 135 year. It is therefore in the best interest of these industries that catch quotas are relatively predictable and stable from year to year. It is well-known that Although fish stocks naturally fluctuate (Hjort 1927), and estimates of stock size are subject to random and systematic errors, it is possible to use past perceptions of the state of the stock to formulate logical functions or algorithms that dictate the quota given the perceived state of the stock. These algorithms are commonly called Harvest Control Rules (HCRs).

\section{Harvest control rules: usefulness and limitations}

The logic of the harvest control rule is that there is a transparent relationship between spawning stock biomass (SSB) and a level of catch or instantaneous fishing mortality rate $(F)$. In 1995, the first ever formalized HCR in Europe was implemented in Iceland for Icelandic cod (Baldursson et al. 1996) followed by North Sea herring in 1997 (Dickey-Collas et al. 2006). Since then, HCRs are the increasingly popular way for scientists and policy-makers to formulate advice and recommendations. Politically, HCRs became important for managers and industry because they are pre-agreed, predictable and tailored to meet objectives for the fishery in the short or medium term (Deroba and Bence 2008). 
152 formulation of HCRs does not allow the underlying uncertainty to explicitly resonate in 153 decision-making. The 2013 ICES advice for Northeast Arctic cod was based on, among other 154 factors, a SSB estimated at 1986000 metric tons, where the relative standard error is likely to 155 be $>10 \%$ of that estimate (Aanes et al. 2013) due to, among other factors, fairly large sampling errors in the input estimates of abundance indices and catch in numbers at age (Aanes and Vølstad 2015).

The current HCR for Northeast Arctic cod has been politically negotiated between Norway and Russia to include a special stability clause in the formulation (Eikeset et al. 2012; ICES 2015). With some exceptions, this clause states that the quota next year may not be increased or decreased by more than $10 \%$ from last year's. This means that if the quota last year was $500000 \mathrm{t}$, then next year's quota typically should be larger than $450000 \mathrm{t}$ but no larger than $550000 \mathrm{t}$. The main reasoning behind this clause is to provide predictable quotas from year to year for the industry, but it is clear that the current HCR cannot be relied on if drastic changes, positive or negative, occur to the fish stock or to the perception of the size of the fish stock. In other words, if the assessment of the size of a fish stock is poorly estimated one year, for example due to reduced sampling effort in monitoring programs that delivers key input-data, this error will propagate directly into the stock assessment quota advice dictated by the HCR for the following year.

\section{Uncertainty}

A prediction is based on a model, and the error is given by the model and data. The actual mechanism for generating the error in stock assessment is complex and not well known. In this paper, we consider two main types of errors in stock assessments. The first are random sampling errors associated with the data input from multi-stage sample surveys to the assessment model (Hirst et al. 2012; Aanes and Vølstad 2015), often assumed to be independent identically log normal distributed errors (Myrseth et al. 2011). The second type is 
177 empirical error, which results from the assessment process itself. Empirical errors contain

178 both the systematic error and the random error, and may be quantified by comparing time-

179 series of actual assessments to converged stock assessment results. For example, the one year 180 prediction from the ICES Arctic Fisheries Working Group (AFWG) Reports (1991-2004)

181 compared to the converged VPA is most closely associated with the converged VPA the year

182 before. The annual estimates of the number of Northeast Arctic cod of age 7+ (a proxy for the 183 spawning stock) from 1995 to 2010, for example, where 17\% higher than the ICES 2010 184 estimates back in time, on average (min 77\% and max 163\%) (Pennington et al. 2011, p. 580, 185 Table 10.3.4). Later studies based on data all the way from 2015 (ICES 2015) have shown even larger retrospective bias for the period 2008-2010 annual estimates.

Examples of methods to assess uncertainty in stock assessment and population dynamics models are provided in McCallistair et al. (1994), Patterson et al. (2001), Aanes et al. (2007), Magnusson et al. (2013), Maunder and Punt (2013), Methot and Wetzel (2013), and Nielsen and Berg (2014). In this study, we assume that adequate methods exist to quantify uncertainty when we apply confidence intervals around the predicted input of a harvest control rule. Previous studies (e.g. Myrseth et al. 2011) have assessed uncertainty in stock predictions by introducing random independent and identically distributed (iid) errors in the model. There is evidence from the AFWG stock assessments that random iid errors alone do not represent the total error adequately due to the restrospective bias (ICES 2014a). We know there are uncertainties from different sources in stock estimates, but the central question of 197 this study is: Can we design harvest rules that are robust to both iid and empirical uncertainties? And will these these new formulations of HCRs out-perform the status quo? To test this, we quantify this total error empirically and experiment with four formulations of harvest control rules, described below, with a population model calibrated for the Northeast Arctic cod. 


\section{Confidence Interval Harvest Control Rule}

204

Since fish stock assessments will always vary in quality, it is important that uncertainties in the assessment are communicated in the fisheries advice. It is therefore we propose the Confidence Interval HCR (CI-HCR) as an alternative to the traditional HCR based on point estimates of SSB and $F$. The CI-HCR takes into account estimates of the inherent uncertainty within the stock assessment estimate of stock size, for example due to sampling errors in input data, and gives a range (a confidence interval) of the quantitative spread associated with the point estimate. The CI-HCR is fulfilled by choosing a certain percentile of that distribution, representing the amount of "risk" a decision-maker is willing to accept in the stock estimate. Prager and Shertzer (2010) describe a very similar approach derived from and tailored to policy needs in the United States. Like Prager and Shertzer, we hypothesize that such probability-based methods will help scientists communicate the quality In addition to this formulation, we also design and test two alternative formulations of the CI-HCR, described below.

Methods

To explore the performance of the CI-HCR compared to the status quo, we first formulate a generic three parameter HCR that is dependent on an input parameter of biomass

222 from a stock assessment. We then explicitly use the uncertainty of the input estimate by considering its distribution, which enables us to determine the confidence intervals of the input. 

through their life together with a Ricker recruitment model fitted to data for Northeast Arctic cod to assess the performance of a generic harvest control rule. The baseline on which we judge performance is a generic HCR with only one reference point parameterized such that it resembles the observed historical population dynamics and catches given by ICES (2014b) provided no uncertainty in estimates of population parameters enters the HCR.

In the following section, we describe essential portions of the population dynamical model and the formulation and application of the CI-HCR.

\section{Model}

We apply the usual cohort model for population abundances for successive ages:

where $N_{a, y}$ is the population abundance, $F_{a, y}$ the fishing mortality, and $M_{a, y}$ the natural mortality at age $a$ in year $y$. Stock development is generally highly sensitive to assumptions made about natural mortality (e.g. Quinn and Deriso 1999; Aanes et al. 2007; Bjørkvoll et al. 2012). Although attempts have been made for modeling the process for natural mortality for NEA cod (Aanes et al. 2007), the management advice is based on a constant natural mortality across age-classes and time but adding an age- and time-varying mortality due to cannibalism (ICES 2014b). For simplicity and consistency with the actual assessment for NEA cod, we adopt the most common assumption and set natural mortality constant and equal 0.2 (e.g. Quinn and Deriso 1999; ICES 2014b; ICES 2015). The total catch is linked to the model through the general catch relationship:

$$
C_{a, y}=\frac{F_{a, y}}{F_{a, y}+M_{a, y}}\left(1-e^{-F_{a, y}-M_{a, y}}\right) N_{a, y}
$$


252 Notice that the fishing mortality $(F)$ is the unknown variable estimated by solving this 253 equation.

254

255

256

257

258

259

260

261

262

263

264

265

266

267

268

269

270

271

272

273

274

\section{Recruitment}

We follow Aanes et al. (2007) and model recruitment as a Ricker function with lognormally distributed variability:

$$
\mathrm{N}_{\mathrm{a}_{\text {min }}, \mathrm{y}}=\alpha \mathrm{S}_{\mathrm{y}-\mathrm{a}_{\min }} \exp \left(-\beta \mathrm{S}_{\mathrm{y}-\mathrm{a}_{\mathrm{min}}}\right) \exp \left(\varepsilon_{\mathrm{a}, \mathrm{y}}^{\mathrm{R}}\right)(3)
$$

where $\varepsilon_{a, y}^{R} \stackrel{i i d}{\sim} N\left(0, \sigma_{R}^{2}\right)$.We replaced the parameters $\alpha, \beta$, and $\sigma_{R}^{2}$ with the maximum likelihood estimates obtained from the data set 1946-2009 for recruits at age 3 and spawning stock biomass (in tons) available from ICES (2014) $\left(\alpha=0.76, \beta=-8.60 \times 10^{-7}\right.$, and $\sigma_{R}=0.65$, with adjusted R-square 0.29), such that the numbers at age 3 can be generated based on the spawning stock biomass 3 years before and a sample of $\varepsilon_{a, y}^{R}$ from the distribution $N\left(0, \sigma_{R}^{2}\right)$

\section{The harvest control rule formulations}

We formulate our HCR as a catch-based rule, and not as a rule based on the estimated fishing mortality rate ( $F$-based rule). There are some advantages to our simple formulation. First, HCRs based on catch are geometrically simpler than an F-based rule, since the latter rule has inherent non-linearity. Since communication and dialogue with stakeholders is an important component in fisheries management (ICES 2008; Paramor et al. 2005; Dankel et al. 2008; Jentoft and McCay 1995), it is more intuitive to use catch-based rules based on actual catches when possible rather than abstract rate-based rules like $F$-based rules. Other 
275 advantages to using catch-based rules are that they are computationally simpler after the 276 relationship between catch and fishing mortality rate is established. To test the effect of stock

277 prediction uncertainty under different harvest rules, we formulated four versions of harvest 278 control rules (HCRs). The basis of these HCRs is a generic formulation including three 279 parameters and has well known harvesting strategies as special cases depending on the exact 280 parameterization. We apply the numerical values of these parameters that best match the 281 current HCR for Northeast Arctic cod, our model stock. In our experiments, the quota is given 282 by each of the four HCRs.

\section{Formulation 1: The generic harvest control rule}

We define the generic harvest control rule used as a basis of the study as:

$$
\operatorname{TAC}_{\mathrm{y}}=\left\{\begin{array}{cc}
\mathrm{C}_{0}+\alpha\left(\mathrm{x}_{\mathrm{y}}-\mathrm{x}_{\lim }\right), & \mathrm{x}_{\mathrm{y}}>\mathrm{x}_{\lim } \\
\mathrm{C}_{0} \frac{\mathrm{x}_{\mathrm{y}}}{\mathrm{x}_{\lim }}, & \mathrm{x}_{\mathrm{y}} \leq \mathrm{x}_{\lim }
\end{array}\right.
$$

where, $\mathrm{TAC}_{y}$ is the total allowable catch at time $y, C_{0}+\alpha\left(x_{y}-x_{\mathrm{lim}}\right)$ is the target catch which is interpreted as a minimal catch $C_{0}$ plus a proportion $\alpha$ of the population status, $x_{y}$ above the threshold, or limiting point, $x_{\lim }$. If the population falls below the limiting point $x_{\lim }$, the harvest is reduced linearly with rate $C_{0} / x_{\lim }$ by $x_{y}$. The rule is illustrated in Figure 1 and includes four well known harvesting strategies:

1. Constant harvesting $\mathrm{TAC}_{y}=C_{0}$ if $x_{\lim }=0$ and $\alpha=0$

2. Proportional harvesting $\mathrm{TAC}_{y}=\alpha x_{y}$ if $C_{0}=0$ and $x_{\lim }=0$

297

3. Threshold harvesting; harvesting everything above the threshold $\mathrm{x}_{\mathrm{lim}}$, i.e. $\mathrm{TAC}_{y}=x_{y}-x_{\lim }$ if $x_{y}>x_{\lim }$ and 0 otherwise. If $C_{0}=0$ and $\alpha=1$ 
4. Proportional threshold harvesting: Harvesting a proportion of the population

299

300

301

302

303

304

305

306

307

308

309

310

311

312

313

314

315

316

317

318

319

320

above the threshold $x_{\lim }$, i.e. $\alpha\left(x_{y}-x_{\lim }\right)$

To match the current HCR for Northeast Arctic cod, we define $x_{y}$ as spawning stock biomass at time $y$ and $x_{\lim }$ as the constant limiting value of spawning stock biomass similar to the precautionary spawning stock level $B_{\mathrm{pa}}$ (ICES 2014b) as a measure of the lowest population level considered to define a safe biological limit. In reality $x_{y}$ is unkown and is predicted based on the most current assessment estimates, $\tilde{x}_{y}$.

\section{Formulation 2: Confidence interval HCR}

One simple way of making the HCR directly dependent on the uncertainty in the assessment and the prediction is to replace $\tilde{x}_{y}$ by the $p$ 'th percentile of its sampling distribution of $\tilde{x}_{p, y}$. This statistic correspond to the one sided confidence interval of the estimate for the true value $x_{y}$, and consequently, a more precise prediction should on average yield a higher TAC since the $\tilde{x}_{p, y}$ is closer to $x_{y}$ than a more imprecise prediction. In this paper, we choose $p=0.2$ which corresponds to a one-sided $80 \%$ confidence interval for illustrational purposes.

\section{Formulation 3: Interval HCR}

To approach a system with more predictable quotas, we define a set of $n$ possible quotas $\mathrm{TAC}=\left\{\mathrm{TAC}_{1}, \ldots, \mathrm{TAC}_{\mathrm{n}}\right\}$ based on transferring stock assessment model predictions into discrete numbers. Quotas are discretized on $\mathrm{TAC}$ by rounding $\mathrm{TAC}_{\mathrm{y}}$ derived from the first formulation (eq. 4) to the nearest $\mathrm{TAC}_{i}$ in $\mathrm{TAC}$ which we denote $\mathrm{TAC}_{y}^{*}$. The discretized version of the HCR is illustrated in Figure 2. For the case study presented here we have defined TAC with quotas from 0 to 2000000 tons (the highest reported total catch for NEA cod is 1.34 million tons in 1956) with interval lengths 100000 tons. 


\section{Formulation 4: Interval HCR and confidence interval}

The last formulation we will consider is the combination of the confidence interval HCR and the interval HCR. More, specifically we apply the $p$ 'th percentile of its sampling distribution of $\tilde{x}_{p, y}$ to the $\mathrm{HCR}$ (eq. 4) to obtain $\mathrm{TAC}_{y}$, and then we find the $\mathrm{TAC}_{y}^{*}$ which is closest to the values the set of possible quotas TAC defining the implemented quota.

\section{Defining the HCR input}

The spawning stock biomass is $x_{y}=\sum_{a} p_{a, y} w_{a, y} N_{a, y}$ where $p_{a, y}$ is the proportion of mature fish in the stock and $w_{a, y}$ is the weight of fish at age $a$ in year $y$, respectively. We assume that the proportion mature fish and weight at age is constant over time and within year, i.e. $p_{a, y}=p_{a}$ and $w_{a, y}=w_{a}$, respectively, and we parameterize this as average across years by age for estimates provided by ICES (2014b).

To be able to fully implement the proposed HCR, additional assumptions on how the quota is linked to the catch and distributed among ages is necessary. We explain this in the following section.

\section{From quota in tons to numbers at age: Exploitation pattern}

First, we assume that the actual total catch in a given year equals the TAC without any implementation error, such that total yearly catch is defined by:

$$
\mathrm{TAC}_{y}=\sum_{a} w_{a} C_{a, y}
$$

For simplicity we assume that weight at age of fish in the total catch equals weight at age of fish in the stock. To determine how the catches differ among age-classes we consider the exploitation pattern defined through the exploitation fraction in year $y$ at age $a$. The exploitation fraction $\mu_{a, y}$ is defined by:

$$
C_{a, y}=\mu_{a, y} N_{a, y}
$$


Then, the exploitation fraction is decomposed into an age specific fishing pattern $s_{a}$

344

and a year specific exploitation fraction $\mu_{y}$ based on a separability assumption, i.e. $\mu_{a, y}=$ $s_{a} \mu_{y}$ (see e.g. Quinn and Deriso 1999, p 331). The age specific exploitation pattern $s_{a}$ is scaled to the interval $\{0,1\}$ such that $s_{a}=1$ for fully recruited ages. This means that $\mu_{y}$ is the exploitation fraction for fully recruited ages. We use data on catches and population sizes available from ICES (2014b) to estimate the $s_{a}$ 's. We calculate the average instantaneous fishing mortality $(F)$ from yearly estimates provided by the AFWG reports (ICES 2014b; ICES 2015).

Since $\mathrm{TAC}_{y}=\sum_{a} w_{a} C_{a, y}=\sum_{a} w_{a} s_{a} \mu_{y} N_{a, y}$ it follows that $\mu_{y}=\frac{\mathrm{TAC}_{y}}{\sum_{a} w_{a} s_{a} N_{a, y}}$, and thus the catch at age in numbers is given by $C_{a, y}=\mu_{a, y} N_{a, y}$ such that the sum over ages, accounting for the weight at age, equals $\mathrm{TAC}_{y}$.

\section{Simulating predictions with uncertainty}

To obtain realistic simulations to assess the performance of an HCR, it is important to be able to simulate SSB prediction errors realistically. The actual error in the prediction is complex to quantify and depend on several sources of variability such as the uncertainty in the input data used for assessing the stock (Aanes and Vølstad 2015; Hirst et al. 2012), the length of time series to estimate processes, environmental stochasticities and uncertainty in parameter estimates for processes (Lande et al. 2003). In this paper we assess the effect of the uncertainty by reasonable approximations based on assuming an error structure on the prediction used in the HCR without explicitly accounting for the underlying complex mechanism actually causing the variability. The most common assumption is to assume that random errors in stock assessment have zero mean and are independent and identically distributed (iid) within and across years (cf. Myrseth et al. 2011). We adopt the same approach (iid error) by assuming that $\tilde{x}_{y}$ is $\log$ normally distributed with mean $x_{y}$ and 
367

368

369

370

371

372

constant variance on the log scale. However, errors in stock assessment often appear to be serially correlated such that the abundance is over- or underestimated in several following years causing retrospective bias (Hurtado-Ferro et. al 2014 and references therein).

To test the iid error assumption we use empirical data and establish an empirical model for the prediction based on converged VPA estimates of stock abundance. More specifically, we use the converged VPA for NEA cod for the most recent year from ICES (2014b), then we collect values for the annual one-year forecast predictions available from ICES (1991 through 2014, except for 1991 and 1998 for which no value was available). By empirical data analysis of predictions vs VPA estimates (using predictions for the years 19912009 omitting the most recent years due to lack of convergence of VPA) we find that the model

$$
\log \left(\tilde{x}_{y}\right)=\beta \log \left(x_{y-1}\right)+\varepsilon_{y}^{P}
$$

where $\varepsilon_{y}^{P} \sim N\left(0, \sigma_{P}^{2}\right)$, describes the predictions very well $\left(\beta=1.007, \sigma_{p}=0.263\right.$, adjusted Rsquare 0.999 ). We refer to this approach as simulating predictions with empirical error. In this case we relate the error directly to $\varepsilon_{y}^{P}$ since it is implicitly assumed that the systematic component is fixed and given by the underlying assessment method. In both cases we assume that the variance and the distribution are known such that quantiles from the distribution (i.e. confidence intervals) can be found.

\section{Parameterizing the HCR}

First we need to calibrate the status quo HCR in the same model as the CI-HCR. In this paper we parameterize the HCR in such a way that it resembles the behavior of the implemented HCR currently in use for this stock, where no uncertainty in the prediction of SSB is directly taken into account used in the HCR. To achieve this we use the same limiting reference point as the one applied in the implemented HCR for NEA cod, i.e. $x_{\lim }=B_{\mathrm{pa}}=$ $460000 \mathrm{t}$. We set $C_{0}=212000 \mathrm{t}$ which corresponds to the historical lowest reported catch 
391 from AFWG. Finally, we find that by setting $\alpha=0.8$ in this strategy (with the described 392 parameterization for the recruitment process and selection pattern), the mean annual yield 393 becomes $\sim 1$ million tons, with a mean fishing mortality for ages 5-10 $F=0.36$. For 394 comparison, the empirical long-term yield and fishing mortality is $\sim 0.66$ million tons and 395 $F \sim 0.61$, respectively, whereas $F_{\mathrm{pa}}=0.4$.

396

397

398

399

400

401

402

403

404

405

406

407

408

409

410

411

412

413

414

415

\section{Evaluating performance}

To adequately quantify performance statistics for a given HCR it is necessary to simulate each HCR for a long time in order to ensure that the process has reached stationarity and thus stabilize the statistics in terms of mean values, variances and associated risks. We choose 500 time steps after an initialization period of 100 time steps. The performance statistics are: 1) loss in mean annual yield, 2) mean fishing mortality, 3) coefficient of variation in mean annual yield, and 4) the probability of the spawning stock biomass being lower than $B_{\text {lim }}=220000$ tons as defined by ICES (ICES 2014b). Loss in mean annual yield is the percentage reduction in mean annual yield by applying the same HCR on predictions with a specified level of uncertainty.

We simulated the operating model forward for two different characterizations of uncertainty (independent identical random error and empirical error) for four different tactical formulations of a generic harvest control rule parameterized for our illustration using NEA cod: the generic HCR, the confidence interval HCR, the interval HCR, and the hybrid confidence interval + interval HCR. We measured the performance of these four HCRs with the following indicators averaged over the simulated time period: the percent loss of mean average yield, the mean fishing mortality rate $(F)$, the coefficient of variation of annual yield and the probability that the biomass falls below the reference biomass level, $B_{\text {lim }}$. Figure 3 shows the results.

\section{Results}


The $\mathrm{x}$-axis in Figure 3 represents relative standard error (RSE) in percent (Jessen 417 1978), which is the standard error of the survey estimate divided by the survey estimate multiplied by 100. In face of increasing uncertainty (x-axis Figure 3), the status quo HCR for NEA cod performs worst in regards to CV of annual yield and probability of the SSB dropping below the limit SSB reference point. This is mainly due to the fact that the status quo HCR is not able to account for a more precautionary harvest rate when the underlying uncertainty in the assessments increases. However, both formulations of the confidence interval HCR (the CI-HCR and the hybrid CI and interval HCR) performs much better than the status quo in keeping $F$ low when faced with increasing uncertainty (relative standard error, Figure 3 x-axis).

The cost in terms of lost harvest of a more precautionary HCR formulated with confidence intervals is interesting. For the first uncertainty characterization (independent identical log-normally distributed random errors) the CI-HCR performs poorest. However, we see that the benefit of the CI-HCR is evident when faced with empirical error. In Figure 3 (top row), the percent loss of the mean annual yield is highest for the status quo formulation of the HCR and lowest for the CI-HCR. This means that the status quo HCR for NEA cod is not robust to "known unknowns" regarding the accuracy of the annual stock assessment.

\section{Discussion and Conclusions} around the world, are scientifically-advised with annual catch recommendations that consist a single number. Since these numbers will always incorporate different types of uncertainty, it is of utmost importance to 1) test the recommended catch's robustness to different types of uncertainty, and 2) have a clear and transparent dialogue with the resource users and decision- 
441 formulation of harvest control rules for fish stocks that depend on a point estimate of the size 442 of the stock. The underlying and inherent uncertainties associated with that number are not made explicit and accessible for decision-makers and stakeholders in all the arenas in which that number plays a role. In order to align the risks associated with quota setting, we propose an alternative formulation of HCRs by applying the associated confidence interval around the point estimate.

There are additional benefits with the CI-HCR framework, including possibility of prioritizing survey effort in relation to quota and associated risk to the fish population. A method described by Aanes et al. (2013) gives the opportunity to use statistical assessments models that can quantify confidence limits for SSB and $F$. Thus by using this methodology, the propagation of error from input data to the assessments and then in the HCR is made more transparent for the decision-maker. The simple concepts developed here could be further and within year. Although as pointed out by Marshall et al. (1998) spawner biomass may not be a sensitive measure of the reproductive and recruitment potential of Northeast Arctic cod. 
2013) support the hypotheses that productivity may vary and discuss the importance of developing HCRs and reference points that take this into account (i.e. the robustness of the harvest control is not really tested with respect to the important sources of uncertainty). Our simulation approach is based on a VPA and therefore mainly considers only uncertainty in observations and process such as recruitment. However, uncertainty about the actual dynamics (i.e. model uncertainty) has a larger impact on achieving management objectives (Punt 2008).

Management strategy evaluation (MSE) is the state-of-the-art framework for testing the robustness of different management regimes in fisheries (Smith et al. 1999; Rademeyer et al. 2007; Punt et al. 2014) and has been applied in many specific cases (e.g. Cox and Kronlund 2008; Dankel and Edwards in press; Dichmont et al. 2006; Needle 2008; Polacheck et al. 1999). Likewise, the CI-HCR catch-setting framework we propose here could be further tested among other candidate HCRs with a variety of plausible stock assessment models in an MSE framework for our example of NEA cod or any other fish stock with enough data and explicit objectives. This testing, however, goes beyond the scope of this paper, since MSE should ideally be designed and conducted with and for stakeholders and decision-makers (Smith et al. 1999; Rademeyer et al. 2007).

The important larger processes involved in fisheries management (i.e. of agreeing what uncertainties to consider and how to evaluate trade-offs) are strengthened once the scientists and decision-makers are clear about the underlying quality of the assessment. ICES, as well as other regional science-advice institutions, is committed to providing the best quality science for management and policy advice. The ICES Planning Group on Data Needs for Assessment and Advice (PGDATA) is working on methods to properly document uncertainty in input data from fisheries dependent and fisheries independent surveys. Thus, this important information needs to be connected to management advice and quota setting. The central point 
491 in this paper is that confidence intervals around a point estimate show the quality of the 492 assessment more explicitly. This is a way for science to be more transparent about the quality 493 of the advice, and for decision-makers and society to understand when precaution is

494

495

496

warranted. The results we show in this paper lend support to the application of a CI-HCR formulation in future studies testing robust fisheries strategies.

Why could some scientists, decision-makers and stakeholders disagree with the CIHCR framework? Rosenberg (2007) and Kraak et al. (2010) outline reactions from fisheries scientists who are reluctant to share uncertainties with stakeholders and policy-makers, though the dangers of doing so have already been exposed in other scientific arenas that are dependent on high-quality scientific assessments (Keepin and Wynne 1984; Wynne 1992; Kloprogge and Van der Sluijs 2006; Van der Sluijs 2007; Van der Sluijs et al. 2008; Dankel et al. 2012). But uncertainty and risk are involved in all decision-making. When managing a common pool natural renewable resource, it behooves the manager and society to have appropriate frameworks, including a transparent documentation of precisely what known risks are taken and at what time. Currently, HCRs do not necessarily take into account data quality in a transparent manner. Thus, quota advice may not reflect varying quality of data from commercial catch sampling programs and scientific surveys, which depend on survey design, sampling effort, and choice of estimators (e.g., Aanes and Vølstad, 2015). The CI-HCR proposed here provides a basis for such transparency by explicitly choosing a percentile of confidence to dictate changes in a quota, instead of changes determined by random variation in point estimates of SSB, typically the mean or median value.

The success of the outcomes of the science-policy interface can hinge on the ability to use the most relevant tools for the task at hand. For fisheries quota advice, the tools needed are ones that are robust to the uncertainties inherent in the scientific understanding of the fisheries system. More work, testing and dialogue in the community is needed to fully endorse 
516 harvest rules that explicitly encompass uncertainties. But in the current state of change we are

517 witnessing in the North Atlantic and other ecosystems (abiotic and climate change, change in

518 fish distributions, as well as political unrests on settling quotas), we suggest that this dialogue 519 begin now.

520

\section{Acknowledgements}

522 The authors thank the conveners and participants in the Hjort Symposium in Bergen October 5232014 for feedback on this study, in addition to the constructive reviews from the associate 524 editor and two anonymous reviewers. All of the authors were supported by the "Adaptive 525 management of living marine resources by integrating different data sources and key 526 ecological processes (ADMAR)" funded by the Research Council of Norway, 200497/I30.

\section{References}

528

529

530

Aanes, S., Engen, S., Sæther, B.-E., and Aanes, R. 2007. Estimation of the parameters of fish stock dynamics from catch-at-age data and indices of abundance: can natural and fishing mortality be separated? Canadian Journal of Fisheries and Aquatic Sciences 64(8): 1130-1142.

Aanes, S., and Vølstad, J.H. 2015. Efficient statistical estimators and sampling strategies for estimating the age composition of fish. Canadian Journal of Fisheries and Aquatic Sciences 72(6): 938-953.

Aanes, S., Subbey, S. and Vølstad, J.H. 2013. Assessing adequate level of catch- and surveymonitoring for stock assessment and estimation of biological reference points for Northeast Arctic Cod. ICES 2013 ASC/J:07.

Baldursson, F.M., Danielsson, A., and Stefánsson, G. 1996. On the rational utilization of the icelandic cod stock. . ICES Journal of Marine Science 53(4): 643-658. 
541

542

543

544

545

546

547

Bjørkvoll, E., Grøtan, V., S., A., Sæther, B.-E., Engen, S., and Aanes, R. 2012. Stochastic Population Dynamics and Life-History Variation in Marine Fish Species. . The American Naturalist 180(3): 372-387.

Charles, A.T. 1998. Living with uncertainty in fisheries: analytical methods, management priorities and the Canadian groundfishery experience. Fisheries Research 37: 37-50.

Cooke, J.G. 1999. Improvement of fishery-management advice through simulation testing of harvest algorithms. ICES Journal of Marine Science: Journal du Conseil 56(6): 797-810.

Dankel, D.J., Aps, R., Padda, G., Röckmann, C., van der Sluijs, J.P., Wilson, D.C., and Degnbol, P. 2012. Advice under uncertainty in the marine system. ICES Journal of Marine Science: Journal du Conseil. 69(1), 3-7.

Dankel, D.J., Skagen, D.W., and Ulltang, Ø. 2008. Fisheries management in practice: A review of 13 commercially-important fish stocks Reviews in Fish Biology and Fisheries 18 201-233.

Dankel, D.J., and Edwards, C.T.T. 2016. Fishery systems and the role of management science. In Fisheries Management Science: an introduction to simulation based methods. Edited by C.T.T. Edwards and D.J. Dankel. Earthscan (Routledge), Oxford, 448 pp. In press.

Deroba, J.J., and Bence, J.R. 2008. A review of harvest policies: Understanding relative performance of control rules. Fisheries Research 94(3): 210-223.

Dichmont, C.M., Deng, A., Punt, A.E., Venables, W., and Haddon, M. 2006. Management strategies for short lived species: The case of Australia's Northern Prawn Fishery: 2. Choosing appropriate management strategies using input controls. Fisheries research 82(1-3): 221-234.

Dickey-Collas, M., Skagen, D., and Simmonds, J. 2006. Harvest Control Rules and Changing Productivity: the working example of North Sea Herring. ICES ASC. 
566 Eikeset, A.M., Richter, A.P., Dankel, D.J., Dunlop, E.S., Heino, M., Dieckmann, U., and 567 Stenseth, N.C. 2013. A bio-economic analysis of harvest control rules for the Northeast $568 \quad$ Arctic cod fishery. Marine Policy 39(0): 172-181.

569

570

571

572

573

574

575

576

577

578

579

580

581

582

583

584

585

586

587

588

589

Fay, G., Tuck, G.N., Haddon, M., and Klaer, N.L. 2012. Maintaining risk equivalency among fishery harvest control rules in the SESSF. In Tuck, G.N. (ed.) 2012. Stock Assessment for the Southern and Eastern Scalefish and Shark Fishery 2011. Australian Fisheries Management Authority and CSIRO Marine and Atmospheric Research, Hobart.

Francis, R. C. 2011. Data weighting in statistical fisheries stock assessment models. Canadian Journal of Fisheries and Aquatic Sciences, 68(6), 1124-1138.

Hauge, K.H. 2010. Uncertainty and hyper-precision in fisheries science and policy. Futures doi: 10.1016/j.futures.2010.10.006.

Hegland, T.J., and Hopkins, C.C. 2014. Towards a new fisheries effort management system for the Faroe Islands? Controversies around the meaning of fishing sustainability. Maritime Studies 13(1): 1-24.

Hilborn, R. 2003. The state of the art in stock assessment: where we are and where we are going. Scientia Marina 67(S1): 15-20.

Hirst, D., Storvik, G., Rognebakke, H., Aanes, S., and Vølstad, J.H. 2012. A modeling approach to the estimation of catch-at-age of commercial fish species. Canadian Journal of Fisheries and Aquatic Sciences 69: 1-13.

Hjort, J. 1926. Fluctuations in the year classes of important food fishes. Journal du Conseil 1(1): 5-38.

Holm, P. and Nielsen, K.N. 2004. The TAC Machine. In Appendix B, Working Document 1. In: ICES 2004 Report of the Working Group for Fisheries Systems (WGFS). Annual Report. Copenhagen, Denmark. 
Hurtado-Ferro, F., Szuwalski, C.S., Valero, J.L., Anderson, S.C., Cunningham, C.J., Johnson, K.F., Licandeo, R., McGilliard, C.R., Monnahan, C.C., Muradian, M.L., Ono, K., VertPre, K.A., Whitten, A.R., and Punt, A.E. 2015. Looking in the rear-view mirror: bias and retrospective patterns in integrated, age-structured stock assessment models. ICES Journal of Marine Science: Journal du Conseil 72(1): 99-110.

ICES. 2008. Report of the Study Group on Management Strategies (SGMAS).

ICES. 2014a. Report of the third Workshop on Practical Implementation of Statistical Sound Catch Sampling Programmes, 19-22 November 2013, ICES HQ, Copenhagen, Denmark. ICES CM2013/ACOM:54. 109pp.

ICES. 2014b. Report of the Arctic Fisheries Working Group (AFWG), 2014, Lisbon, Portugal. ICES CM 2014/ACOM:05. 656 pp.

ICES. 2015. Report of the Arctic Fisheries Working Group (AFWG), 23-29 April 2015, Hamburg, Germany. ICES CM 2015/ACOM:05. 639 pp.

Jentoft, S., and McCay, B. 1995. User participation in fisheries management - Lessons drawn from international experiences Marine Policy 19: 227-246.

Jessen, R. J. (1978). Statistical Survey Techniques. John Wiley \& Sons. New York. 520pp.

Johnsen, J.P., Holm, P., Sinclair, P., and Bavington, D. 2009. The Cyborgization of the Fisheries: on Attempts to Make Fisheries Management Possible. Maritime Studies 7(2): 9-34.

Keepin, B., and Wynne, B. 1984. Technical analysis of IIASA energy scenarios. Nature 312(5996): 691-695.

Kloprogge, P., and van der Sluijs, J.P. 2006. The inclusion of stakeholder knowledge and perspectives in integrated assessment of climate change. Climatic Change 75(3): 359389. 
614 Kraak, S., Kelly, C., Codling, E., and Rogan, E. 2010. On scientists' discomfort in fisheries 615 advisory science: the example of simulation-based fisheries management strategy 616 evaluations. Fish and Fisheries 11: 119-132.

617 Lande, R., Engen, S., and Sæther, B. 2003. Stochastic Population Dynamics in Ecology and 618 Conservation. Oxford University Press

619 Magnusson, A., Punt, A.E., and Hilborn, R. 2013. Measuring uncertainty in fisheries stock 620 assessment: the delta method, bootstrap, and MCMC. Fish and Fisheries 14: 325-342.

621 Marshall, C. T., Kjesbu, O. S., Yaragina, N. A., Solemdal, P., and Ulltang, Ø. 1998. Is 622 spawner biomass a sensitive measure of the reproductive and recruitment potential of 623 northeast arctic cod? Canadian Journal of Fisheries and Aquatic Sciences, 55(7):1766$624 \quad 1783$.

625 Maunder, M.N., and Punt, A.E. 2013. A review of integrated analysis in fisheries stock 626 assessment. Fisheries Research 142: 61-74.

627 McAllister, M.K., Pikitch, E.K., Punt, A.E., and Hilborn, R. 1994. A Bayesian approach to 628 stock assessment and harvest decisions using the Sampling/ Importance Resampling 629 Algorithm. Canadian Journal of Fisheries and Aquatic Science 51: 2673-2687.

630 Methot, R.D., Tromble, G.R., Lambert, D.M., and Greene, K.E. 2013. Implementing a 631 science-based system for preventing overfishing and guiding sustainable fisheries in the 632 United States. ICES Journal of Marine Science: Journal du Conseil.

633 Methot, R.D., and Wetzel, C.R. 2013. Stock synthesis: A biological and statistical framework 634 for fish stock assessment and fishery management. Fisheries Research 142: 86-99.

635 Myrseth, J., Enberg, K., Heino, M., and Fiksen, Ø. 2011. Do accurate stock estimates increase 636 harvest and reduce variability in fisheries yields? Natural Resource Modeling 24: 222637 241. 
638 Needle, C.L. 2008. Management strategy evaluation for North Sea haddock. Fisheries $639 \quad$ Research 94(2): 141-150.

640 Nelson, G. A. (2014). Cluster Sampling: a pervasive, yet little recognized survey design in 641 fisheries research. Transactions of the American Fisheries Society, 143(4): 926-938.

642 Nielsen, A., and Berg, C.W. 2014. Estimation of time-varying selectivity in stock assessments 643 using state-space models. Fisheries Research 158: 96-101.

644 Paramor, O.A.L., Hatchard, J.L., Mikalsen, K.H., Gray, T.S., Scott, C.L., and Frid, C.L.J. 645 2005. Involving fishers in the development of a fisheries ecosystem plan. In ICES CM 646 Patterson, K., Cook, R., Darby, C., Gavaris, S., Kell, L., Lewy, P., Mesnil, B., Punt, A., 647 Restrepo, V., Skagen, D.W., and Stefánsson, G. 2001. Estimating uncertainty in fish 648

649

650

651

652

653

654

655

656

657

658

659

660

661 stock assessment and forecasting. Fish and Fisheries 2: 125-157.

Pennington, M., Shevelev, M.S., Vølstad, J.H., and Nakken, O. 2011. Chapter 10.3 Bottom trawl surveys. In: The Barents Sea. Ecosystem, resources, management. Half a century of Russian-Norwegian cooperation, pp. 570-584. Ed. by T. Jakobsen. and V.K. Ozhigin, V.K. Tapir Academic Press, Trondheim.

Polacheck, T., Klaer, N.L., Millar, C., and Preece, A.L. 1999. An initial evaluation of management strategies for the southern bluefin tuna fishery, pp. 811-826.

Prager, M.H., and Shertzer, K.W. 2010. Deriving Acceptable Biological Catch from the Overfishing Limit: Implications for Assessment Models. North American Journal of Fisheries Management 30(1): 289-294.

Punt, A. E. 2008. Refocusing Stock Assessment in Support of Policy Evaluation. T. K. K. Tsukamoto, T. Takeuchi, T. D. Beard, Jr. and M. J. Kaiser, eds. Fisheries for Global Welfare and Environment, 5th World Fisheries Congress 2008, pp. 139-152. Copyright by TERRAPUB 2008 . 
662 Punt, A.E., Butterworth, D.S., de Moor, C.L., De Oliveira, J.A.A., and Haddon, M. 2014. 663 Management strategy evaluation: best practices. Fish and Fisheries. DOI: $664 \quad 10.1111 /$ faf.12104.

665 Punt, A. E., A’mar, T., Bond, N. A., Butterworth, D. S., de Moor, C. L., De Oliveira, J. A., 666 Haltuch, M. A., Hollowed, A. B., and Szuwalski, C. 2013. Fisheries management under 667 climate and environmental uncertainty: control rules and performance simulation. ICES 668 Journal of Marine Science: Journal du Conseil.

669 Quinn, T.J., and Deriso, R.B. 1999. Quantitative Fish Dynamics Oxford University Press.

670 Rademeyer, R.A., Plaganyi, E.E., and Butterworth, D.S. 2007. Tips and tricks in designing 671 management procedures. ICES Journal of Marine Science 64(4): 618-625.

672 Rosenberg, A.A. 2007. Fishing for certainty. Nature 449(7165): 989-989.

673 Shepherd, J. G. 1999. Extended survivors analysis: An improved method for the analysis of 674 catch-at-age data and abundance indices. ICES Journal of Marine Science: Journal du $675 \quad$ Conseil, 56(5): 584-591.

676 Smith, A. D. M., Sainsbury, K.J. and Stevens, R.A. 1999. Implementing effective fisheries677 management systems - management strategy evaluation and the Australian partnership 678 approach. ICES Journal of Marine Science 56(6): 967-979.

679 Subbey, S., Devine, J.A., Schaarschmidt, U., and Nash, R.D. 2014. Modelling and forecasting 680 stock-recruitment: current and future perspectives. ICES Journal of Marine Science $681 \quad$ 71(8): 2307-2322.

682 Szuwalski, C., and Punt, A.E. 2012. Identifying research priorities for management under 683 uncertainty: The estimation ability of the stock assessment method used for eastern 684 Bering Sea snow crab (Chionoecetes opilio). Fisheries Research 134-136(0): 82-94. 
685 Szuwalski, C. S., Vert-Pre, K. A., Punt, A. E., Branch, T. A., and Hilborn, R. (2014). 686 Examining common assumptions about recruitment: a meta-analysis of recruitment 687 dynamics for worldwide marine fisheries. Fish and Fisheries.

688

689

690

691

692

693

694

695

696

697

698

699

700

701

702

703

704

705

706

707

708

709

van der Sluijs, J. P., Craye, M., Funtowicz, S. O., Kloprogge, P., Ravetz, J. R., \& Risbey, J. S. 2005. Combining quantitative and qualitative measures of uncertainties in model based environmental assessment: The NUSAP system. Risk Analysis, 25(2), 481-492.

van der Sluijs, J.P. 2007. Uncertainty and precaution in environmental management: Insights from the UPEM conference. Environmental Modelling \& Software 22(5): 590-598.

van der Sluijs, J.P., Petersen, A.C., Janssen, P.H.M., Risbey, J.S., and Ravetz, J.R. 2008. Exploring the quality of evidence for complex and contested policy decisions. . Environmental Research Letters 3(024008).

Vert-pre, K. A., Amoroso, R. O., Jensen, O. P., and Hilborn, R. 2013. Frequency and intensity of productivity regime shifts in marine fish stocks. Proceedings of the National Academy of Sciences, 110(5):1779-1784.

Wilson, D.C. 2009. The Paradoxes of Transparency: Science and the Ecosystem Approach to Fisheries Management in Europe. University of Amsterdam Press, Amsterdam.

Wilson, D.C., and Pascoe, S. 2006. Delivering Complex Scientific Advice to Multiple Stakeholders. Elsevier.

Wynne, B. 1992. Uncertainty and environmental learning: Reconceiving science and policy in the preventive paradigm. Global Environmental Change 2(2): 111-127.

\section{Table and Figure captions}

Table 1. A comparison of the scientific advice for total allowable catches (TAC) and the negotiated TACs (by the Joint Norwegian Russian Fisheries Commission) and the implemented TACs for Northeast Arctic cod. The TACs are expressed as metric tonnes. 
711 Figure 1. An illustration of the generic formulation of the harvest control rule (HCR). The x-

712 axis represents the size of the point estimate of the fish stock, $\tilde{X}$. The y-axis is the TAC as a

713 result of the combination of the parameters $C_{0}, \alpha, x_{\lim }$. The green lines show the rule for

$714 x_{\lim }=0$ and different levels of $\alpha$. Red lines indicate the harvest rule where for $C_{0}=0$ and

715 different levels of $\alpha$. The black lines show an intermediate formulation of the HCR. The 716 constant harvesting strategy is fulfilled if $\alpha=0$.

717

718

Figure 2. Illustration of discretized HCR (see text) as quota TAC by a predicted stock

719 parameter $(\tilde{X})$. In this example quota is discretized into seven quota categories $\left(\mathrm{TAC}_{1}\right.$ to

$720 \mathrm{TAC}_{7}$ ). The continuous HCR which forms the basis for deciding a quota category is shown by

721 broken lines.

722

723

Figure 3. Four formulations of harvest control rules and their performance for four criteria

(percent loss of mean average yield (MAY), mean fishing mortality rate $(F)$, coefficient of variation of annual yield, and risk to the population dropping below the limit reference point for the spawning stock) for increasing levels of relative standard error (RSE, x-axis). The lefthand column represents analysis of only independent identical log-normally distributed (iid) assessment model. 
1

2 Table 1

\begin{tabular}{|l|l|l|l|}
\hline Year & $\begin{array}{l}\text { ICES (Scientific) TAC Advice } \\
\text { (http://www.ices.dk/sites/pub/Publicati } \\
\text { on\%20Reports/Advice) }\end{array}$ & $\begin{array}{l}\text { Agreed (Negotiated) TAC } \\
\text { (www.regjeringen.no) }\end{array}$ & $\begin{array}{l}\text { Estimated Actual } \\
\text { (Implemented) TAC } \\
\text { (ICES AFWG Report } \\
\text { 2015, Table 3.1a) }\end{array}$ \\
\hline 2010 & 703000 & 607000 & 609983 \\
\hline 2011 & 751000 & 703000 & 719829 \\
\hline 2012 & 940000 & 751000 & 727663 \\
\hline 2013 & 993000 & 1000000 & 966209 \\
\hline 2014 & 894000 & 894000 & 986449 \\
\hline
\end{tabular}

3

4 


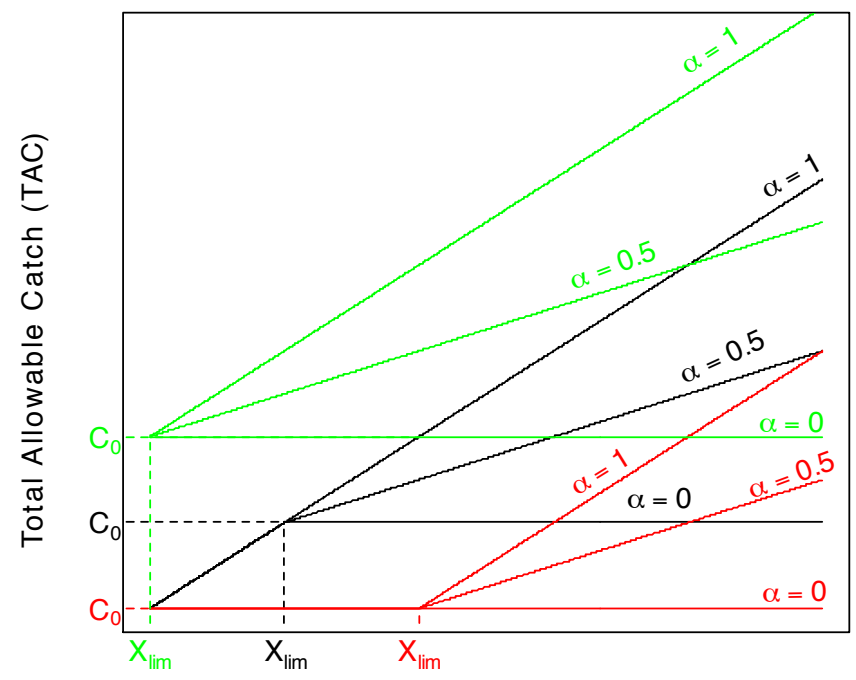

Stock Estimate, $\tilde{X}$ 


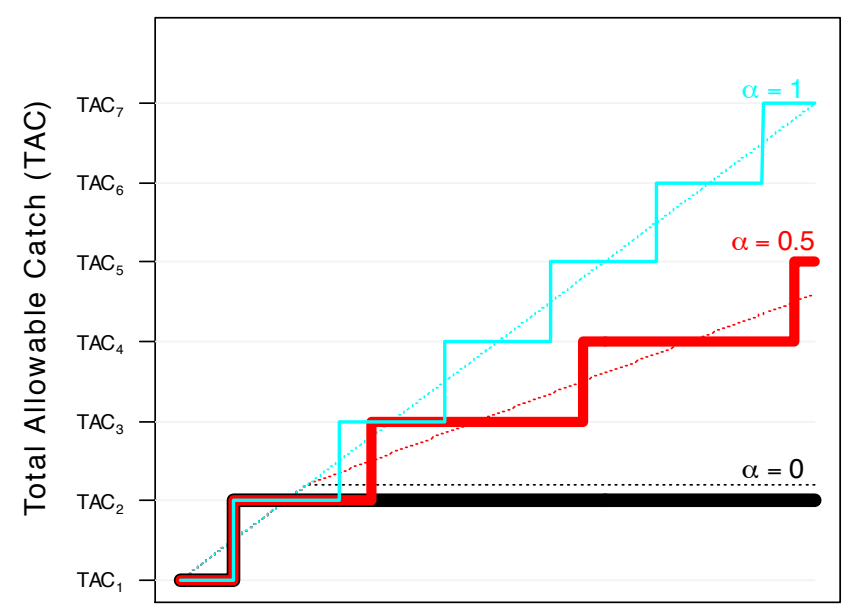

Stock Estimate, $\widetilde{X}$ 


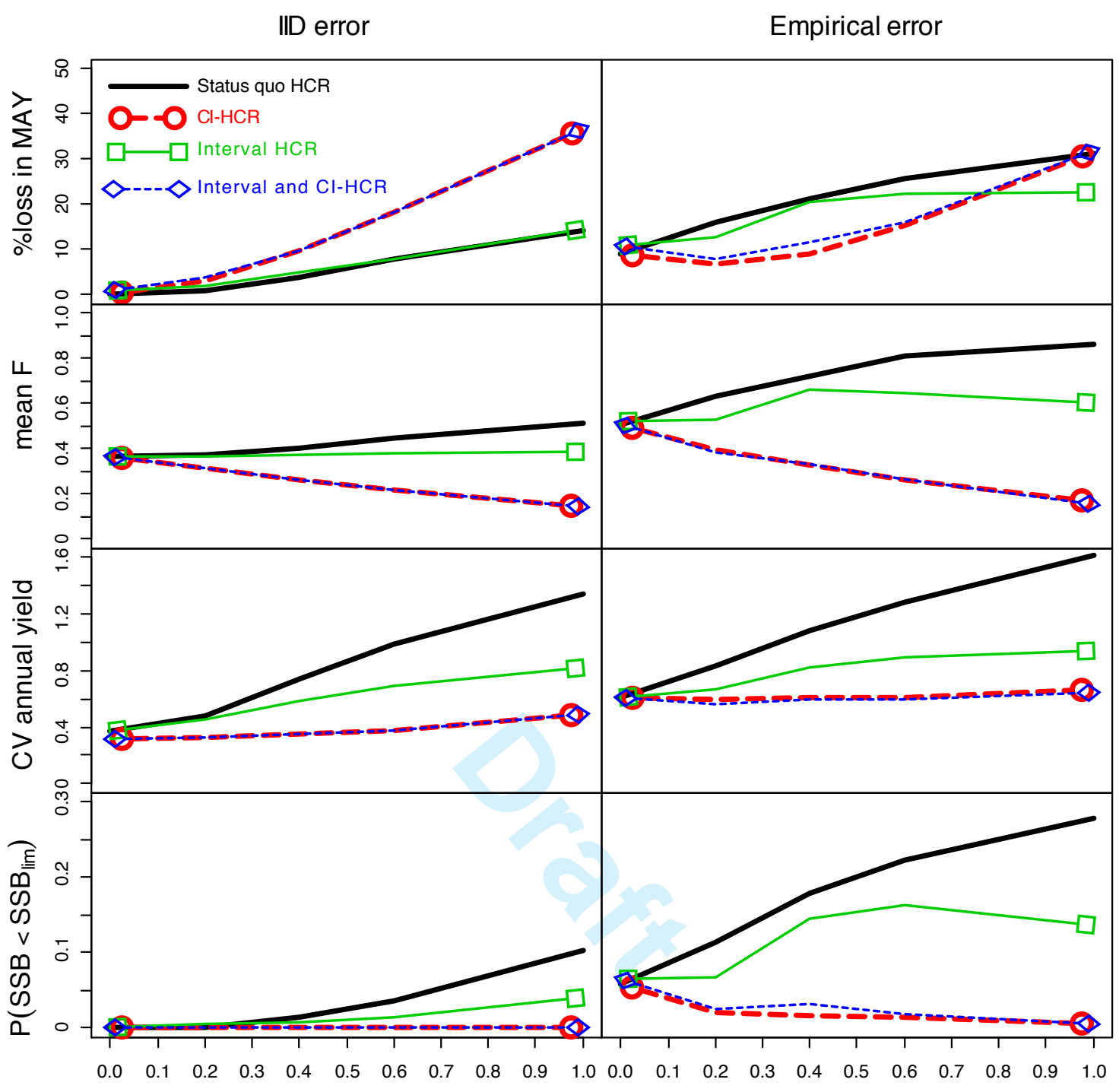

Relative Standard Error (RSE) 